Locomotion : some bones, joints and muscles of lower leg, ankle and foot in man and in primate "predecessors"

Non Peer-reviewed author version

NARAIN, Faridi; VAN ZWIETEN, Koos Jaap; Lamur, Kenneth; Kosten, Lauren; De Munter, Stephanie; Piskun, Oleg \& Zinkovsky, Anatoly (2011) Locomotion : some bones, joints and muscles of lower leg, ankle and foot in man and in primate "predecessors". In: Lesgaft notes.

Handle: http://hdl.handle.net/1942/11874 


\section{LOCOMOTION: SOME BONES, JOINTS AND MUSCLES OF LOWER LEG, ANKLE AND FOOT IN MAN AND IN PRIMATE "PREDECESSORS"}

Faridi Hélène Muriël Narain, medical doctor, former junior lecturer, Anton de Kom University, Paramaribo

Koos Jaap van Zwieten, medical doctor, doctor of medical sciences, professor, University of Hasselt, Diepenbeek

Kenneth Siegfried Lamur, doctor of movement sciences, professor, Anton de Kom University, Paramaribo

Lauren Kosten, bachelor of biomedical sciences, junior trainee master's programme in clinical molecular sciences,

Stephanie De Munter, bachelor of biomedical sciences, junior trainee master's programme in clinical molecular sciences, University of Hasselt, Diepenbeek

Oleg Jevgenievitch Piskun, candidate of pedagogical sciences, senior lecturer, Anatoly Victorovitch Zinkovsky, doctor of biological sciences, professor, St. Petersburg State Polytechnical University, St. Petersburg

\section{Annotation}

The article presents widening of spaces between certain lower leg and ankle bones, during power stroke of normal gait. Repositioning of these bones after this widening, normally occurring during recovery, can be analysed functional morphologically and comparative anatomically. For this, opossums are studied, as primate "predecessors".

Key words: foot, ankle, comparative anatomy, inversion traumatisms, gymnasts

\section{INTRODUCTION}

Recently, the two characteristics "widening of the spatium interosseum antebrachii" and "narrowing of the spatium interosseum antebrachii" were introduced to indicate supination and pronation respectively, two phenomena concerning the non-sagittal movements of the two bones in the lower arm [18]. In supination, the radius lies more or less parallel to the ulna; in pronation the radius crosses over the ulna [5]. So, the more parallel the positions of these bones are, the wider is the spatium interosseum antebrachii between them; the more these bones are crossing each other, the narrower is the spatium interosseum antebrachii between them.

Quadrupedal locomotion in primates, the hand clinging to the substratum while the body moves forward, does impose such movements as described above to the lower arm, as a consequence of the inevitable concomitant rotation of the upper arm around its longitudinal axis [6]. Most of the higher primates including man show internal rotation of the humerus (the bone in the upper arm) at the very beginning of the power stroke, after which the humerus gradually rotates externally during the power stroke. The radius then gradually crosses over the ulna, while the hand - palm downwards - stays in contact with the substrate. Remarkably, modern man e.g. sitting at a table shows essentially the same when he shifts a PC-mouse from a rather remote position towards his body, over e.g. a horizontal mouse-mat, his hand palm downwards holding the mouse while the mouse stays in contact with the mouse-mat. 
Here too, the narrowing of the spatium interosseum antebrachii is one of the hallmarks of pronation, in the human lower arm [18].

Further it is evident, from logical reasoning as well as by analysing real-time motion sequences, that predecessors of primates such as the opossum e.g. during walking on a conveyor belt or during beam-walking, have their humerus externally rotated at the beginning of power stroke $[4,13]$. As the power stroke continues while the animal moves forward, the humerus rotates internally as long as the hand stays in contact with the substrate [1]. As revealed by cineradiography, radius and ulna then gradually uncross, which is defined as supination, with the widening of the spatium interosseum antebrachii as its hallmark [4,13]. During the forelimb's subsequent recovery phase, in such primate predecessors as the opossum, the humerus then rotates externally during which the hand is held more or less palm downwards [4]. Consequently, pronation of the lower arm is then observed in the forelimb recovery phase, hallmarked by narrowing of the spatium interosseum antebrachii [4].

Recognising these characteristics does provide unmistakeable advantages, in human anatomy as well as in mammalian quadruped morphology, because both characteristics can be checked in vitro in the laboratory, and in vivo by e.g. palpation, and even by cineradiography $[4,13]$. Several practical ergonomic applications have been proposed, after introducing these fundamental analyses [3]. Therefore the question arose, as to whether such characteristics can also be recognised in the lower limb of man, respectively in the hind limb of a primate predecessor, viz. the opossum. To answer this question, several observations were carried out, starting from anatomical specimens of these remote species - representing respectively a primate predecessor (opossum) and a primate (man).

\section{METHODOLOGY}

A limited number of dry osteological specimens and wet anatomical specimens present in our department of anatomy, each of them alternately demonstrating osteology, arthrology and myology in situ of human lower leg and foot, as well as of the hind limb of opossum Didelphis marsupialis, were observed, photographed and described. Wet anatomical specimens were supple enough to be manipulated in vitro, so as to be used to simulate live movements. Such movements were then compared to in vivo motion analyses, if necessary to archival footage. Standard radiography as well as HR-imaging techniques served to indicate easy-to-recognise anatomical bony landmarks. Two early $19^{\text {th }}$ century accounts on the behaviour and anatomy of marsupials, published in Russia and in England, helped to identify certain somewhat overlooked structures and their functions, to be currently found in marsupials [15,2].

\section{EXPERIMENTAL}

In man, the osteological and arthrological complex of tibia and fibula in the lower leg is generally considered as being minimally mobile, due to its rigidity. Therefore 
attention was paid to some more distal joints, namely those between the ankle bones calcaneus and talus proximally, and cuboid and navicular distally. The common joint between these first two (proximal) bones, and the last two (distal) bones, is called the transverse mid tarsal joint of Chopart. While their toes were kept immobilised so that they stayed firmly in contact with the flat substratum, a number of normal anatomical specimens showing arthrology of lower leg and foot were x-rayed from laterally, in positions equivalent to mid stance, push-off and extreme inversion of foot at push-off [In inversion, the sole of the foot turns inward, facing medially; in eversion it turns outward, facing laterally. Inversion implies supination of the foot, while eversion implies pronation of the foot.] The resulting radiographs simulating in vivo sequences from mid stance to push-off, were carefully studied - mainly in a qualitative manner.

With respect to the common Surinam opossum Didelphis marsupialis, anatomical specimens of its hind limbs demonstrating arthrology and myology were observed with the use of binoculars. The joints between tibia and fibula in many marsupials are traditionally seen as mobile [20,19]. Their range of motion was studied, as was the functional morphology of the joints between tibia, fibula, and some ankle bones. Structural and functional findings were already published [19,10,9]. Therefore we concentrated also on myology, by the use of microdissection and HR-imaging. With regard to aspects of gait analyses, special attention was paid to recovery phases of the hind limb in Didelphis marsupialis as well as in Didelphis ursina Shaw 1800 [2]. Results were correlated to primates, man included, and also to lower tetrapods [9,14].

\section{RESULTS AND DISCUSSION}

In man, bones of the ankle - also known as the tarsus - show the following. During inversion of the foot in a representative lower leg specimen, starting from the mid stance position toes staying in contact with the substratum, while rest of the foot is gradually brought to extreme inversion, the transverse mid tarsal joint of Chopart shows its joint space more clearly. Joint spaces between talus and navicular (more superior), and calcaneus and cuboid (more inferior) gradually widen, presenting themselves as one continuous line. Chopart's joint line, S-formed or worm-like in situ, presents itself as a lightly undulating line in a lateral view. On radiographs these two lines intersect nearly perpendicularly. A space present between bony surfaces of talus and calcaneus, known as sinus tarsi or "eye of the ankle", becomes "wide open" Its talocalcaneal interosseus ligament in-between normally restrains further widening The common opossum Didelphis marsupialis, when walking deliberately over rather flat surfaces, keeps its foot clinging to the substratum during the whole power stroke, the very end of which is characterised by an extreme inversion of its foot. The various arthrological mechanisms of its lower leg and ankle during these sequences have been sufficiently described $[9,10,19]$. A well-developed astragalo-calcaneal interosseus ligament or ligamentum cervicale, around the neck of the talus, seems to play a key role in this extreme inversion. In such inversion of the opossum foot, tibia and fibula rotate externally around their longitudinal axes. By the mobility of joints connecting them the spatium interosseum cruris between tibia and fibula now widens 
Most interesting are internal and external features of the opossum lower leg, ankle and foot, during the recovery phase of quiet walking over flat surfaces. Starting with toe-off, the foot immediately everts to be kept horizontally, mostly during the mid recovery phase $[9,11]$. This foot repositioning is accompanied by internal rotations of tibia and fibula, while the spatium interosseum cruris between them becomes narrow

With regard to recovery, the internal rotations of tibia and fibula accompanied by the process of approaching each other, as indicated by the narrowing of the spatium interosseum cruris, are supposedly caused by a muscle, that was probably identified already two centuries ago [2]. [The marsupial in question then classified as Didelphis ursina Shaw 1800 or Opossum hirsutum Perry 1810, is known as the wombat. The deep interosseus muscle in the marsupial lower leg was called $m$. peroneotibialis [12] but the eversion of the opossum foot during its recovery phase was not yet reported.] Based upon the course of this $m$. interosseus cruris stretching from fibula to tibia, as also seen in transverse sections, internal rotations of tibia and fibula in the swinging leg during its recovery phase may (at least partly) be attributed to this muscle indeed.

Comparing these results with some of the relevant literature, it is first noted that in normal human gait, push-off at the end of the stance is currently characterised by a certain degree of inversion of the foot, but not by an extreme inversion [9]. Nevertheless positions of extreme inversion of the foot can be attained, as the in vitro observations demonstrated. Then, the importance of the talocalcaneal interosseus ligament in restraining the opening of the sinus tarsi at such positions is emphasised. In the opossum, the possible key role of the comparable ligamentum cervicale during otherwise typical extreme inversion of the foot at push-off, underlines its importance. Presence of such a ligamentum cervicale in marsupials was until recently denied [7].

The simultaneity or coupling of external rotation by the lower leg to inversion of the foot - and vice versa the coupling of internal rotation by the lower leg to eversion of the foot - is not confined to just predecessors of primates like opossums. It is seen in humans as well. Kinetic backgrounds of this coupling were sufficiently described [8].

In certain reptiles, activities of a muscle, comparable to the marsupial m. interosseus cruris, were recently reported. In walking turtles, lower leg $m$. pronator profundus is active during most of their stance, as well as during part of their recovery phase [14]. In man moreover, comparable $m$. popliteus is most active in a free swinging leg [16].

In early $19^{\text {th }}$ century literature on the wombat, there is an understandable lack of reports on the immediate eversion of its foot, at the start of its recovery phase $[2,15]$. Naturalists focused on digging behaviour of their Wombatus fossor Desmarest 1804 [fossor=digger]. To dig, animals of course need some lower leg internal rotation [2]. Only recently, eversion of the foot coupled to lower leg internal rotation at recovery, was reported in analysing marsupial behaviour as seen in Didelphis marsupialis [9].

Finishing these comparisons, we like to emphasise that in normal human gait, lack of eversion of the foot during the recovery phase easily elicits a "landing-on-theslightly-inverted-foot", which in turn may cause a so-called "inversion traumatism". 
In fact, inversion traumatisms of the ankle are very frequent traumatisms in sports, leisure and daily activities [17]. A pilot study in young gymnasts however, clearly demonstrated that proactive training of muscles that cause eversion of the foot, leads to better ankle stability [11]. Therefore our analyses support such preventive training.

\section{CONCLUSIONS}

Our question as to whether certain anatomical spaces between bones of the lower leg do actually widen during normal gait, in man representing primates and in the common opossum representing predecessors of primates, can be answered positively. This is based on in vitro observations of anatomical specimens of both species and on the simulations of motion with the help of these specimens, supported by additional studies of gait in vivo, mainly based on archive footage present in our department.

In man, during walking, the foot at the end of stance at push-off shows but a modest inversion which however can be exaggerated to a more extreme inversion of the foot. Then, the tarsal joints like Chopart's joint and also the sinus tarsi clearly show their joint spaces on radiography. Normally the talocalcaneal interosseus ligament restrains this widening. During gait, a foot that is landing after its recovery phase, may accidentally do so in a position of inversion, thus risking a so-called inversion traumatism. Training proactively e.g. the peroneus muscles (evertors of the foot) may prevent the incidence of such traumatisms, as suggested by a pilot-study in gymnasts.

In the opossum Didelphis marsupialis lower leg, during normal quiet walking, the spatium interosseum cruris present between tibia and fibula gradually widens in stance during the power stroke. This reflects concomitant external rotations of these bones, coupled to extreme inversion of the foot as well, which lasts until the end of push-off. Although denied in marsupials until recently, the opossum's strong astragalocalcaneal interosseus ligament or ligamentum cervicale underlines the importance of our observations [7, 19]. From the very onset of recovery, the opossum shows eversion of its foot, to a horizontal position at mid recovery. This eversion is coupled to internal rotations of both fibula and tibia in the free leg as is also reflected by the narrowing of the spatium interosseum cruris in the opossum. The course of $m$. interosseus cruris described two centuries ago in a marsupial (the wombat), stretching from fibula to tibia, suggests its possible active role in this process of repositioning. All mechanisms show a unique locomotion, in primate "predecessors". Although representing quite remote species, structures of lower limbs in man and opossum show many similarities of their Bauplan with regard to osteology and arthrology. Our observations illustrate the typical "human" of structures and functions in the lower leg, ankle and foot. Suggestions to train proactively those muscles of the lower leg that prevent the most frequent sport traumatism, namely the so-called inversion traumatism of the ankle, logically emanate from our present study 


\section{BIBLIOGRAPHY}

1. Gambaryan, P. P. Cinefluorographical study of the burrowing movements in the common mole, Talpa europaea (Lipotyphia, Talpidae) / P. P. Gambaryan, J.-P. Gasc, S. Renous // Russian Journal of Theriology. - 2002. - Vol. 1, Issue 2. - P. 91-109

2. Home E. An account of some peculiarities in the anatomical structure of the wombat / E. Home // Philosophical Transactions of the Royal Society. - 1808. Vol. 98, Part 2. - P. 304-312

3. http://www.handshoemouse.com/research.html

4. Jenkins, F. A. Limb posture and locomotion in Virginia opossum (Didelphis marsupialis) and in other non-cursorial mammals / F. A. Jenkins // Journal of Zoology, London. - 1971. - Vol. 165, Issue 3. - P. 303-315

5. Lambrichts, D. The role of the pronator teres muscle in the arm during the rowing movement, at the end of the stroke / D. Lambrichts, K. J. van Zwieten, P. L. Lippens, K. P. Schmidt, S. Hauglustaine // Proceedings of the $2^{\text {nd }}$ International Congres on "Sport and Health" 21-23 April, 2005, St. Petersburg - 2005. - ISBN 5-94988-012-9, P. 358-359

6. Larson, S. G. Maintenance of above-branch balance during primate arboreal quadrupedalism: coordinated use of forearm rotators and tail motion / S. G. Larson, J. T. Stern // American Journal of Physical Anthropology. - 2006. - Vol. 129, Issue 1. - P. 71-81

7. Lewis, 0. J. The joints of the evolving foot. Part II. The intrinsic joints // Journal of Anatomy. - 1980. - Vol. 130, Issue 4. - P. 833-857

8. Maestro, M. Rappel biomécanique des articulations talo-crurale et sous-talienne / M. Maestro // Médecine et Chirurgie du Pied. - 2004. - Vol. 20, Issue 1. - P. 610

9. Narain, F. H. M. Human foot inversion prior to toe-off: an analysis by means of functional morphology, and comparative anatomical observation / F. H. M. Narain, K. J. van Zwieten, P. Gervois, P. L. Lippens, A. Reyskens, P. Colla, Y. Palmers, K. P. Schmidt, M. Vandersteen, S. Biesmans, I. Robeyns, B. Op 't Eijnde, A. V. Zinkovsky, S. A. Varzin, K. S. Lamur // Journal of Vibroengineering. - 2009. - Vol. 11, Issue 3. - P. 530-535

10. Narain, F.H.M. Aspects of arthrology in the lower leg of the opossum / F.H.M. Narain, K.J. van Zwieten, P.L. Lippens, K.S. Lamur // European Journal of Morphology - 2003. - Vol. 41, Issue 1. - P. 68

11. Narain, F.H.M. Possible roles of lower leg muscles involved in foot eversion during swing phases of gait / F. H. M. Narain, A. Brauns, K. Lemmens, K. J. van Zwieten, J. Duysens, S. Hauglustaine, M. Vandersteen, P. L. Lippens, P. Adriaensens, E.Theunissen, J. Gelan, K. S. Lamur // Knowledge for Growth 2011. - FlandersBio, Annual Life Sciences Convention, 7th Edition, May $5^{\text {th }}$, ICC University of Ghent. http://knowledgeforgrowth.be/abstracts-and-posters/

12. Pira, A. Beiträge zur Anatomie des Gorilla. Vergleichend-anatomische Studien. I. Das Extremitätenmuskelsystem / A. Pira // Gegenbaurs Morphologisches Jahrbuch. - 1914. - $48^{\text {ster }}$ Band, $2^{\text {tes }}$ Heft. - P. 167-238 
13. Pridmore, P. Trunk movements during locomotion in the marsupial Monodelphis domestica (Didelphidae) / P. Pridmore / Journal of Morphology. - 1992. - Vol. 211, Issue 2. - P. 137-146

14. Schoenfuss, H. L. Motor patterns of distal hind limb muscles in walking turtles: implications for models of limb bone loading / H. L. Schoenfuss, J. D. Roos, A. R. V. Rivera, R. W. Blob // Journal of Morphology. - 2010. - Vol. 271, Issue 12. - P. 1527-1536

15. Sevastianof, A. Déscription de quelques nouvelles espèces d'animaux, du musée académique / A. Sevastianof // Mémoires de l'Académie Impériale des Sciences de St. Pétersbourg. - 1809. - Tome 1. P. 443-449

16. Stensdotter, A.-K. Knee angle and force vector-dependent variations in open and closed kinetic chain for m. popliteus activation / A.-K. Stensdotter, T. Dalén, C. Holmgren, C. Häger-Ross // Journal of Orthopaedic Research. - 2008. - Vol. 26, Issue 2. - P. 217-224

17. Van Zwieten, K. J. Foot muscles preventing inversion traumatisms / K. J. van Zwieten, I. Robeyns, M. Vandersteen, P. L. Lippens, R. V. Mahabier, K. S. Lamur // Medicine and Science in Tennis. - 2007. - Vol. 12, Issue 2. - P. 34-35

18. Van Zwieten, K. J. Lower arm and hand muscles in focal dystonias - some anatomical and therapeutic apects / K. J. van Zwieten, D. Lambrichts, K. Nackaerts, S. Hauglustaine, K. P. Schmidt, G. J. Bex, A. Mewis, W. Duyvendak, F. H. M. Narain, K. S. Lamur, P. L. Lippens, A. V. Zinkovsky, V. A. Sholukha, A. A. Ivanov, V. V. Potekhin, O. E. Piskùn, S. A. Varzin, I. A. Zoubova // In: S. A. Varzin, O. Y. Tarasovskaya (eds.) Transactions of the 3rd All-Russian Scientific Practical Conference with international participants "Health as the basis of human potential : problems and ways to their solution" November 25 27, 2008, Saint-Petersburg State Polytechnical University, Saint-Petersburg, Russia. - 2008. - P. 353-363

19. Van Zwieten, K. J. Pronation and supination mechanisms in the hindlimb of the opossum / K. J. van Zwieten, F. H. M. Narain, S. U. Borgia // Acta Morphologica Neerlando-Scandinavica. - 1983. - Vol. 21, Issue 4. - P. 333-334

20. Young, A. H. The so-called movements of pronation and supination in the hindlimb of certain marsupials / A. H. Young // Journal of Anatomy and Physiology. - 1881. - Vol. 15, Part 3. - P. 392-394 